\title{
Susceptibility of embryos of Biomphalaria tenagophila (Mollusca: Gastropoda) to infection by Pochonia chlamydosporia (Ascomycota: Sordariomycetes)
}

\section{Lorena Souza Castro ( $\square$ lorenascast@gmail.com )}

Universidade Federal de Viçosa https://orcid.org/0000-0001-6118-485X

Isabella Vilhena Freire Martins

UFES: Universidade Federal do Espirito Santo

Vinícius Menezes Tunholi-Alves

UFRRJ: Universidade Federal Rural do Rio de Janeiro

Ludimila Santos Amaral

UFRRJ: Universidade Federal Rural do Rio de Janeiro

Jairo Pinheiro

UFRRJ: Universidade Federal Rural do Rio de Janeiro

Jackson Victor de Araújo

UFV: Universidade Federal de Vicosa

Caio Márcio de Oliveira Monteiro

UFG: Universidade Federal de Goias

Victor Menezes Tunholi

UFRRJ: Universidade Federal Rural do Rio de Janeiro

\section{Research Article}

Keywords: Schistosoma mansoni, fungus, microbial control, intermediate host

Posted Date: February 22nd, 2022

DOI: https://doi.org/10.21203/rs.3.rs-1363748/v1

License: (c) (1) This work is licensed under a Creative Commons Attribution 4.0 International License.

Read Full License 


\section{Abstract}

The trematode Schistosoma mansoni is a heteroxenous parasite, meaning that during its life cycle needs the participation of obligatory intermediate and definitive hosts. The larval development occurs in aquatic molluscs belonging to the Biomphalaria genus, leading to the formation of cercariae, which emerge to infect the final vertebrate host. For this reason, studies for control of the diseases caused by digenetic trematodes often focus on combating the snail hosts. Thus, the objective of this study was to evaluate the susceptibility of Biomphalaria tenagophila embryos to the fungus Pochonia chlamydosporia (isolate Pc-10) under laboratory conditions. Two experimental groups were formed: the control group, consisting of egg masses not exposed to the fungus; and the treated group, in which the snail egg masses were exposed to mycelium of the fungal isolate (Pc-10). At the end of 15 days, the egg masses were evaluated under a stereomicroscope to analyze the hatching of $B$. tenagophila embryos in both experimental groups. The entire experiment was conducted in duplicate, with five replicates for each repetition (five egg masses/replicate), utilizing a total of 100 egg masses, with 20 to 30 eggs/egg mass. After 15 days of interaction, the exposure to the fungal hyphae bodies significantly impaired the viability of the $B$. tenagophila eggs, inhibiting the embryogenesis process by $83.7 \%$ in relation to the control group. Transmission and scanning electron microscopic images revealed relevant structural alterations in the egg masses exposed to the hyphae action of the fungus, interfering in the development and hatching of the young snails under analysis. These results indicate the susceptibility of $B$. tenagophila embryos to the fungus P. chlamydosporia (isolate Pc-10) and suggests the potential of Pc-10 to be used in the control of parasitic agents, such as $S$. mansoni, but in vivo experiments become necessary.

\section{Introduction}

Mansonic schistosomiasis is endemic in Brazil, showing as etiological agent the trematode Schistosoma mansoni (Ministério da Saúde, 2010). This disease of public health relevance has an acute and/or chronic evolution, where the clinical manifestations range from mild dermatitis to relevant hepatosplenic alterations, characterized by hepatopathies with periportal fibrosis, portal hypertension, splenomegaly and ascites (Bezerra et al. 2004; Lamberton et al. 2014). According to epidemiological reports from official agencies, schistosomiasis affects more than 200 million people in the world annually (WHO, 2020), of which 1.5 million cases occur in Brazil (Ministério da Saúde, 2019).

Various factors contribute to the establishment and dispersal of mansonic schistosomiasis in Brazil, such as the widespread presence of the snails that act as intermediate hosts of the helminth (Gastropoda: Planorbidae); the movement (temporary or permanent) of people from endemic areas; deficient residential and environmental sanitation; and lack of health education of people at risk of infection (Passos and Amaral, 1998; Nacife et al., 2018). Therefore, the control of this parasitosis requires the adoption of measures including effective drug treatment of infected definitive hosts, implementation of public policies to improve sanitary conditions in affected regions, sanitary education of target publics, and population control of the snails that integrate the disease's epidemiological transmission chain (WHO, 2020). 
Snails of the Biomphalaria genus are hermaphrodites, being capable of self- or cross-fertilization; the eggs are laid at batch intervals of 5 to 40, each batch being covered in a mass of gelatinous material, called an egg mass. Young snails hatch after 6 to 8 days and reach maturity in 4 to 7 weeks, depending on the species and environmental conditions (WHO, 1997). According to Paraense (1972), in the presence of temporary aquatic environments, such as training of puddles that gradually reduce, these snails carry out the behavior of burying themselves in the ground, thus assuming amphibious behavior.

According to the United Nations (UN), among molluscicidal substances, a standout is niclosamide (5chloro-N-(2-chloro-4-nitrophenyl)-2-hydroxybenzamide) (Machado, 1982; Cantanhede et al., 2010) as well as copper sulfate $\left(\mathrm{CuSO}_{4}\right)$ (Soares et al., 2019) and calcium cyanamide (CaCN区). Although effective as a molluscicide, these substances are extremely toxic to the environment and human and animal health (Henrioud 2011), so it is not considered safe. Additionally, the use of these molecules for extended periods favoured the selection of resistant snails, making its use in official control programs untenable (Andrews et al. 1982), condition that reinforces the importance of studies aimed at the development of new technologies related to the control of these hosts.

This situation has encouraged the development of alternative control methods, targeting the host snail, involving application of biodegradable substances obtained from plants (Hartmann et al. 2011), alone or in association with pathogenic microorganisms such as entomopathogenic nematodes (Tunholi et al. 2017a, b), bacteria (Cheng 1986; Singer et al. 1997) and fungi (Duarte et al., 2015; Castro et al., 2019). Fungi are widely found in nature and can trigger infectious processes in many organisms, thus acting as natural pathogens. The use of fungi to control pests through bioproducts is already a reality in agriculture, being produced on a commercial scale, to demand this purpose (Chagas et al., 2016). However, little is known about the pathogenicity of fungi against $B$. tenagophila embryos.

Evidence about the susceptibility of $B$. glabrata to aquatic and terrestrial pathogenic fungi has been reported by some researchers (Rocha et al. 2009; Baron et al. 2013). In an experimental study, Duarte et al. (2015) observed impairment of the viability of $B$. glabrata eggs when exposed to the action of conidia and hyphae bodies of Metarhizium anisopliae. Furthermore, Castro et al. (2019) investigated the ovicidal potential of Pochonia chlamydosporia (isolate Pc-10) on eggs of Pseudosuccinea columella. According to them, P. chlamydosporia (Pc-10) induced severe structural alterations in the egg masses of the limned in question, hampering the development and hatching rate of the snails. The results of both studies indicated the possible use of these fungal species in programs for biological control of the snails. Despite these studies, the susceptibility of $B$. tenagophila embryos to the fungus $P$. chlamydosporia has not been described yet.

The objective of this study was therefore to evaluate the susceptibility of $B$. tenagophila embryos to the fungus $P$. chlamydosporia (isolate Pc-10) under laboratory conditions, as possible tool to be used in control of schistosomiasis intermediary hosts.

\section{Material And Methods}




\subsection{Obtaining and cultivating the fungus Pochonia chlamydosporia (Pc-10)}

The isolate Pc-10 of the fungus $P$. chlamydosporia used in the laboratory experiments was obtained from the company Rizoflora Biotecnologia (Rizotec $\AA$ ), located in the city of Viçosa, Minas Gerais, Brazil. The bioproduct in question is a microbiological nematicide, effective in combating nematodes, especially Meloidogyne. The isolate (powder formulation) was cultured in medium containing potato dextrose agar (PDA) for 7 days in a biochemical oxygen demand (BOD) incubator at $27^{\circ} \mathrm{C}$ and $80 \%$ relative humidity $(\mathrm{RH})($ Castro et al., 2019).

\subsection{Obtaining egg masses of Biomphalaria tenagophila}

Specimens of $B$. tenagophila were collected from cattle water troughs and ponds located in the municipality of Alegre ( $20^{\circ} 45^{\prime} 48^{\prime \prime}$ South, $41^{\circ} 32^{\prime} 2^{\prime \prime}$ West), Espírito Santo, Brazil. The adult snails ( $\mathrm{n}=$ 180), having between 32 and $35 \mathrm{~mm}$ of shell diameter, were taken to the Parasitology Laboratory of the Veterinary Hospital of the Centre for Agrarian and Engineering Sciences of Federal University of Espírito Santo (CCAE-UFES), where they were maintained at average temperature of $24^{\circ} \mathrm{C}$ in five glass aquariums containing dechlorinated water with continued mechanical aeration. The snails were fed with lettuce leaves (Lactuca sativa) ad libitum. The aquariums were cleaned weekly, and the lettuce leaves were replenished on alternate days to prevent their fermentation. Polystyrene dishes $\left( \pm 5 \mathrm{~cm}^{2}\right)$ were placed inside the aquariums to act as substrate for oviposition and to obtain the egg masses.

The egg masses used in this study were obtained from generations of a colony of $B$. tenagophila maintained in the laboratory, thus confirming the absence of infections. A total of 100 egg masses were obtained after 24 and 72 hours of their respective postures for laboratory analysis. These were removed from the laying substrate with the support of a sterile stainless-steel spatula. They were examined under a stereomicroscope to confirm the presence of eggs. Only the egg masses containing viable embryos, undergoing development, were selected for the experimental testing. The egg masses, each containing about 20 to 30 eggs, were washed three times in distilled water and placed in sterile conical centrifuge tubes $(50 \mathrm{~mL})$ containing distilled water at room temperature until the start of the tests.

\subsection{Exposure of the egg masses of Biomphalaria tenagophila to the fungus Pochonia chlamydosporia}

Before the start of each test, the viability of the chlamydospore (>95\%) was checked according to the method described by Duarte et al. (2015). The biological product (Rizotec®) used in the execution of the study had a concentration of $5.2 \times 10^{7}$ chlamydospores/g of $P$. chlamydosporia.

Petri dishes $(60 \times 15 \mathrm{~mm})$ with a permanent layer of water on $2 \%$ water-agar medium were used for the experimental exposure of the egg masses $(n=5)$ to the hyphae bodies of the fungus, containing approximately $72 \times 10^{5}$ chlamydospores $/ \mathrm{mL}$ of fungus. These dishes were placed in the centre of larger dishes $(80 \times 15 \mathrm{~mm})$, filled with $2 \mathrm{~mL}$ of distilled water to keep the humidity and other environmental 
conditions favourable to the snails and growth of the fungus (Castro et al., 2019). Then the larger Petri dishes $\left(80 \times 15 \mathrm{~mm}\right.$ ) were sealed with Parafilm ${ }^{\circledR}$ to maintain the relative humidity. These dishes were incubated in the dark at $23 \pm 2{ }^{\circ} \mathrm{C}$ for 15 days. This period, in this temperature condition, ensures the completion of stages of gastrulation, organogenesis and development of germ cells that are part of the embryogenesis process of $B$. tenagophila (Kawazoe, 1976).

Two experimental groups were formed, the control group without exposure to the fungus, and the treated group, with exposure of the egg masses to the fungal isolate Pc-10. The entire experiment was conducted in duplicate, with five replicates for each repetition (five egg masses/replicate), using a total of 100 egg masses and between 2000 to 3000 viable eggs.

The evaluation of the interaction between egg masses of $P$. columella and hyphae bodies of $P$. chlamydosporia (in types 1,2 and 3) was carried out according to the parameters defined by Lýsek and Stěrba (1991).

\subsection{Scanning and transmission electron microscopic (SEM and TEM)}

After incubation for 15 days, the egg masses ( $n=3$ egg masses/group) of both experimental groups (control and treated) inserted in microtubes $(1.5 \mathrm{~mL}$ ) containing a $2.5 \%$ glutaraldehyde solution (Castro et al., 2019). The samples were processed at the Carlos Alberto Redins Laboratory of Cell Ultrastructure (LUCCAR) of Federal University of Espírito Santo (UFES), Brazil.

The samples for SEM analysis were dehydrated in serial solutions of ethyl alcohol at concentrations of $30 \%, 50 \%, 70 \%, 90 \%$ and $100 \%$ for 10 minutes at each concentration. Then each sample was dried to critical point in a TOUSIMIS, Autosamdri®-815 apparatus using $\mathrm{CO}_{2}$, the samples were attached to a metal support with double-sided carbon tape and coated with a layer of gold of approximately $250 \AA$, using a Denton Vacuum Desk V system. The samples were observed under a scanning electron microscope (JEOL JEM-6610, USA).

For TEM, the samples were dehydrated by passage in a rising serial solution of acetone $(50 \%, 70 \%, 90 \%$ and $100 \%$ ), with gradual inclusion in increasing proportions of Epon:acetone, embedded in pure Epon epoxy resin and placed in an oven at $60^{\circ} \mathrm{C}$ for 24 hours for polymerization. After the polymerization, the blocks containing the samples were cut into ultra-thin sections $(60 \mathrm{~nm})$ with an RMC Products Power Tome X ultramicrotome with glass face, collected on copper grids (400 mesh) and contrasted with $0.5 \%$ uranyl acetate and lead citrate (Machado and Souza 1998) for visualization of the biological structures (egg masses and fungi) using a transmission electron microscope (JEOL-JEM 1400, USA).

\subsection{Hatching rate of Biomphalaria tenagophila exposed to the mycelial activity of Pochonia chlamydosporia}

After incubation for 15 days, the egg masses of $B$. tenagophila exposed and not exposed to the fungus were analysed with a stereomicroscope to count the number of hatched snails. The viability of the eggs 
was measured according to the percentage of hatched snails in relation to the total number of eggs laid by the snails in each experimental group during the experiment.

\subsection{Statistical analyses}

The study was carried out in a completely randomized design (CRD) and the Shapiro-Wilk test was applied to confirm the normal distribution of data. The results were expressed as mean \pm standard deviation and subjected to the Student t-test, followed by one-way analysis of variance (ANOVA) and the Tukey-Kramer test $(p<0.001)$ to compare the means (GraphPad Prism Inc. 6.01, R 3.4.1).

\section{Results}

After incubation for 15 days, the exposure to the hyphae bodies of $P$. chlamydosporia (isolate Pc-10) impaired the embryogenesis process of $B$. tenagophila $(p<0.05)$. While the eggs of the control group had a hatching rate of $98 \%(93.95 \pm 2.75)$, the eggs exposed to the mycelial action of the fungus had a hatching rate of only $14.3 \%$ (13.70 \pm 0.78 ) (Fig. 1), demonstrating a proportional efficacy of $83.7 \%$ (when compared to the control group) of the Pc-10 isolate in interfering with the embryogenesis process of $B$. tenagophila.

Based on the observations by scanning and transmission electron microscopy, two types of interaction were noted: type 1 (Fig. 2), characterized by a physiological and/or biochemical effect, exerted here by the chemical action of toxins and enzymes arising from the process of metabolism of the fungus that interfere in the stages of embryogenesis of eggs, without affecting the morphology of the egg shell, where hyphae were observed adhered to the egg mass surface; and type 2 (Fig. 3), indicated by a lithic effect with alteration of the egg shell morphology and impairment of the embryonic development, without hyphae penetration of the egg shell. Type 3 interaction, involving a lithic effect accompanied by altered morphology of the embryo and egg, optimized by penetration of hyphae and internal colonization of the egg, was not observed during the period studied.

Additionally, the images of TEM showed part of the thick mass of eggs, ruptured (Fig. 4A - B) and it was also possible to visualize the structure of the chlamydospore and prolongation of the hyphae (Fig. $4 \mathrm{C}$ ). In the SEM (Fig. 4D - F), it was possible to visualize the ruptured mass of the control group, being the inner part without the presence of hyphae (Fig. 4E). Different from the egg mass that was treated with the fungus (Fig. $4 G-I$ ), where there is the presence of mycelium and hyphae, along with the presence of chlamydospores that colonized the interior.

Melanization was not observed in the egg masses exposed to the fungus (Fig. 5B) from the 15th day of incubation. No fungal growth or melanization occurred in the control group (Fig. 5A).

\section{Discussion}

Unfortunately, many control programs for mollusc species that host parasites of human and animal species, whether of economic interest, companionship or medic, let's look at the example of the 
Biomphalaria, do not have achieved success. The scarcity of chemical molecules with molluscicide potential associated with the ban, by official bodies, of the use of these compounds in the environment contributes in part to this. The present study is the first to characterize, under laboratory conditions, the susceptibility of $B$. tenagophila embryos to the fungus $P$. chlamydosporia. The amphibious behavior demonstrated by this planorbid allows, under natural conditions, its exposure, as well as its postures, to the fungus in question. The results obtained show promise characterizing the ovicidal potential of $P$. chlamydosporia in B. tenagophila.

Studies of the biological instead of chemical control of host snails have been conducted since the 1950s, involving investigation of various species of microorganisms considered to be "control agents" of these populations (Ministério da Saúde 2008). In this context, Tunholi et al. (2017) observed that the experimental exposure of Lymnaea columella to infective juveniles of Heterorhabditis baujardi LPP7 induced parasitic castration and caused a mortality rate of $66 \%$. Previously, Singer et al. (1997) observed the molluscicidal potential of Bacillus sp. against B. glabrata under laboratory conditions, suggesting their use in programs for biological control of mansonic schistosomiasis. Furthermore, Duarte et al. (2015) confirmed the susceptibility of egg masses of B. glabrata to the fungi Metarhizium anisopliae and Beauveria bassiana. These validations support the findings obtained in the present study and accredit the isolate Pc-10 as a potential "control agent" for B. tenagophila.

In the present study, the experimental exposure to the hyphae bodies of $P$. chlamydosporia (Pc-10) inhibited the hatching rate of $B$. tenagophila by $83.7 \%$. In general, fungi are biological agents found naturally in the soil that have are pathogenic to various species of invertebrates (Rocha et al., 2009; Baron et al., 2013). Among the fungal species utilized as biocontrol agents, $P$. chlamydosporia stands out. It is a member of the Ascomycota phylum with global distribution, generally isolated from soils rich in organic matter (Manzanilla-Lopez et al., 2013). It is classified as a facultative parasite of the eggs of molluscs and helminths, as well as a hyperparasite of other types of fungi. For these reasons, it has been extensively used for control of many parasitoses (Zare et al., 2001; Braga and Araújo, 2014)

Braga et al. (2008) evaluated in vitro the effect of $P$. chlamydosporia against $S$. mansoni eggs and found that the exposure to the fungus significantly impaired the egg viability of the trematode in question. According to Escudero et al. (2016), the ovicidal potential of Ascomycota fungi results from the mechanical action imposed by their hyphae bodies during the germination step, associated with the release of exoenzymes such as chitinases and proteases, which compromise the egg tegument, directly interfering in the establishment of the embryo. Among the proteases, the serine-alkaline protease VCP1 stands out by degrading the protein layer that composes the external membrane of helminth eggs, (Braga et al., 2011). In this respect, the interruption of the embryogenesis process in $B$. tenagophila verified in this study might have been the result of similar interactions developed by hyphae of $P$. chlamydosporia (isolate Pc-10) when adhering to the surface of the egg masses of this planorbid, interfering with about $86 \%$ of the hatchability rate of $B$. tenagophila embryos. These results demonstrate the ovicidal capacity of $P$. chlamydosporia on both $S$. mansoni and B. tenagophila egg masses, proving to be a promising alternative in the control of schistosomiasis. 
Recently, the embryotoxic effect of $P$. chlamydosporia against $P$ seudosuccinea columella was described (Castro et al., 2019). Through of scanning and transmission electron microscopies analysis, the authors observed that mycelial growth provoked important alterations in the membranes covering the embryos, contributing to loss of water, electrolytes, carbohydrates (e.g., galactogen) and other nutrients that are essential to the embryonic development of the gastropod (Goudsmit, 1972; Faro et al., 2013). Additionally, Castro et al. (2019) observed that the egg masses exposed to the fungus had a withered aspect, with deep grooves on the surface, probably caused by the nutritional demands of the fungus. This alteration contributed to the $93.15 \%$ inhibition of embryogenesis of the host, suggesting the applicability of the Pc10 isolate in biological control programs. Analogous mechanisms to those possibly occurred in the present study, explaining in part the $85.7 \%$ inhibition of the viability of $B$. tenagophila eggs.

Assessing the effects caused by ovicidal fungi, such as $P$. chlamydosporia, Frassy et al. (2010) observed that only the type 3 effect is considered embryotoxic, capable of compromising the development of embryos from target nematode populations. On the other hand, in the present study, it was possible to observe that type 1 and 2 effects were also able to significantly interfere in the viability of $B$. tenagophila eggs, suggesting the embryotoxic potential of these effects in B. tenagophila eggs.

Duarte et al. (2015) found that the viability of eggs and the maturation of egg masses of B. glabrata diminished significantly after exposure to the conidia and hyphae of $M$. anisopliae. According to the authors, the inhibition of embryogenesis possibly occurred through secretion/excretion of substances resulting from the fungal metabolism, which disseminated in the egg masses and impaired the development of embryos. Associated with this, Przeslawski and Benkendorff (2005) reported evidence that the reduction of the oxygen content inside egg masses of gastropod molluscs is a factor limiting egg viability. Therefore, the mycelial activity of $P$. chlamydosporia (isolate Pc-10) on egg masses of $B$. tenagophila might have caused a deficit of oxygen available to the embryos as well as the release of embryotoxic substances, hindering hatching.

Castro et al. (2019) also reported the occurrence of melanisation of snail egg masses in response to exposure to fungal propagules. Melanin is a hydrophobic and negatively charged pigment, synthesized by oxidative polymerization of phenolic compounds. Its production is a defence mechanism against pathogens that is very important for various invertebrates, including Biomphalaria (Bai et al., 1996; Bahgat et al., 2002). Nevertheless, we did not observe this alteration, corroborating the previous observations of Duarte et al. (2015).

\section{Conclusion}

This study reports for the first time the susceptibility of $B$. tenagophila embryos to infection by $P$. chlamydosporia (isolate Pc-10) under experimental conditions. The proposed method is significant impairing the hatchability of the snail in question, which is an intermediate host of $S$. mansoni. Therefore, the biological mechanism of the fungus can be considered an attractive alternative for control of this intermediate host population density. 


\section{Declarations}

\section{Acknowledgments}

This work was supported in part by the Conselho Nacional para o Desenvolvimento Científico e Tecnológico (CNPq) and Fundação de Amparo à Pesquisa do Estado do Espírito Santo (FAPES).

\section{Conflict of interest}

The authors declare that they have not conflict of interest.

\section{References}

1. Andrews P, Thyssen J, Lorke D (1982) The biology and toxicology of molluscicides, bayluscide. Pharmacol Ther 19:245-295. https://doi.org/10.1016/0163-7258(82)90064-X

2. Bahgat $M$, Doenhoff $M$, Kirschfink M, Ruppel A (2002) Serine protease and phenoloxidase activities in hemocytes of Biomphalaria glabrata snails with varying susceptibility to infection with the parasite Schistosoma mansoni. Parasitol Res 88:489-494. https://doi.org/10.1007/s00436-0020595-6

3. Bai G, Li J, Christensen BM, Yoshino TP (1996) Phenoloxidase activity in the reproductive system and egg masses of the pulmonate gastropod, Biomphalaria glabrata. Comp Biochem Physiol - B Biochem Mol Biol 114:353-359. https://doi.org/10.1016/0305-0491(96)00045-4

4. Baron OL, van West P, Industri B et al (2013) Parental Transfer of the Antimicrobial Protein LBP/BPI Protects Biomphalaria glabrata Eggs against Oomycete Infections. PLoS Pathog 9:1-10. https://doi.org/10.1371/journal.ppat.1003792

5. Bezerra AS, de A, D'Ippolito G, Caldana RP et al (2004) Avaliação hepática e esplênica por ressonância magnética em pacientes portadores de esquistossomose mansônica crônica. Radiol Bras 37:313-321. https://doi.org/https://doi.org/10.1590/S0100-39842004000500003

6. Braga FR, Araujo JM, Silva AR et al (2011) Ação ovicida do extrato bruto enzimático do fungo Pochonia chlamydosporia sobre ovos de Ancylostoma sp. Rev Soc Bras Med Trop 44:116-118. https://doi.org/10.1590/S0037-86822011000100027

7. Braga FR, Araújo JV, Campos AK et al (2008) In vitro evaluation of the action of the nematophagous fungi Duddingtonia flagrans, Monacrosporium sinense and Pochonia chlamydosporia on Fasciola hepatica eggs. World J Microbiol Biotechnol 24:1559-1564. https://doi.org/10.1007/s11274-0079643-9

8. Braga FR, De Araújo JV (2014) Nematophagous fungi for biological control of gastrointestinal nematodes in domestic animals. Appl Microbiol Biotechnol 98:71-82

9. Cantanhede SPD, Marques A, de Silva-Souza M, Valverde N AL (2010) Atividade moluscicida de plantas: uma alternativa profilática. Rev Bras Farmacogn 20:282-288. https://doi.org/http://dx.doi.org/10.1590/S0102-695X2010000200024 
10. Castro LS, Martins IVF, Tunholi VM et al (2019) Ovicidal potential of Pochonia chlamydosporia isolate Pc-10 (Ascomycota: Sordariomycetes) on egg masses of the snail Pseudosuccinea columella (Mollusca: Gastropoda). J Invertebr Pathol 166:107212. https://doi.org/10.1016/j.jip.2019.107212

11. Cheng TC (1986) Biological control studies: Bacteria associated with moribund Biomphalaria glabrata (Mollusca) in the laboratory. J Invertebr Pathol 47:219-224. https://doi.org/https://doi.org/10.1016/0022-2011(86)90049-2

12. Duarte GF, Rodrigues J, Fernandes ÉKK et al (2015) New insights into the amphibious life of Biomphalaria glabrata and susceptibility of its egg masses to fungal infection. J Invertebr Pathol 125:31-36. https://doi.org/10.1016/j.jip.2014.12.013

13. Escudero N, Ferreira SR, Lopez-Moya F et al (2016) Chitosan enhances parasitism of Meloidogyne javanica eggs by the nematophagous fungus Pochonia chlamydosporia. Fungal Biol 120:572-585. https://doi.org/10.1016/j.funbio.2015.12.005

14. Faro MJ, Perazzini M, Correa LR et al (2013) Biological, biochemical and histopathological features related to parasitic castration of Biomphalaria glabrata infected by Schistosoma mansoni. Exp Parasitol. https://doi.org/S0014-4894(13)00090-8 [pii];10.1016/j.exppara.2013.03.020 [doi]

15. Goudsmit E (1972) In: FLORKIN M, Zoology SCHEERB (eds) Carbohydrate and carbohydrate metabolism in Mollusca. Academic P, New York, pp 219-243

16. Hartmann DB, Marim RA, Silva YL et al (2011) Lethality of Synadenium grantii Hook. f. (Euphorbiaceae) extract to snails Biomphalaria glabrata Say, 1818 (Gastropoda, Planorbidae). Arq Ciências Veterinárias e Zool da UNIPAR 14:5-11

17. Henrioud AN (2011) Towards sustainable parasite control practices in livestock production with emphasis in Latin America. Vet Parasitol 180:2-11. https://doi.org/10.1016/j.vetpar.2011.05.026

18. Lamberton PHL, Kabatereine NB, Oguttu DW et al (2014) Sensitivity and Specificity of Multiple KatoKatz Thick Smears and a Circulating Cathodic Antigen Test for Schistosoma mansoni Diagnosis Preand Post-repeated-Praziquantel Treatment. PLoS Negl Trop Dis 8:e3139. https://doi.org/10.1371/journal.pntd.0003139

19. Machado AP (1982) The Brazilian program for schistosomiasis control, 1975-1979. Am J Trop Med Hyg 31:76-86. https://doi.org/10.4269/ajtmh.1982.31.76

20. Machado RD, de Souza W (1998) Desidratação, Inclusão, Ultramicrotomia e Contrastação. Técnicas Básicas de Microscopia Eletrônica aplicada às Ciências Biológicas, 1st edn. Sociedade Brasileira de Microscopia, Rio de Janeiro, pp 22-28

21. Manzanilla-Lopez RH, Esteves I, Finetti-Sialer MM et al (2013) Pochonia chlamydosporia: Advances and challenges to improve its performance as a biological control agent of sedentary endo-parasitic nematodes.J Nematol

22. Ministério da Saúde. Secretaria de Vigilância em Saúde. Departamento de Vigilância Epidemiológica (2010) Doenças infecciosas e parasitárias: guia de bolso, 8th edn. Brasília

23. Ministério da Saúde (2014) Vigilância da Esquistossomose Mansoni - Diretrizes técnicas, 4th edn. Brasília 
24. Ministério da Saúde (2008) Vigilância e controle de moluscos de importância epidemiológica: diretrizes técnicas: Programa de Vigilância e Controle da Esquistossomose (PCE). 178

25. Nacife MBPe, Siqueira SL, Martins LMV R, et al (2018) Prevalence of schistosomiasis mansoni in indigenous Maxakali villages, Minas Gerais,Brazil. Rev. do Inst. Med. Trop.São Paulo 60

26. Organization WH (1997) Vector control: methods for use by individuals and communities. 412

27. Passos A, Amaral R (1998) Esquistossomose mansônica: aspectos epidemiológicos e de controle. Rev Soc Bras Med Trop 31:61-74

28. Przeslawski R, Benkendorff K (2005) The role of surface fouling in the development of encapsulated gastropod embryos. J Molluscan Stud 71:75-83. https://doi.org/10.1093/mollus/eyi010

29. Rocha LFN, Tai MHH, dos Santos AH et al (2009) Occurrence of invertebrate-pathogenic fungi in a Cerrado ecosystem in Central Brazil. Biocontrol Sci Technol. https://doi.org/10.1080/09583150902789337

30. Singer S, Van Fleet AL, Viel JJ, Genevese EE (1997) Biological control of the zebra mussel Dreissena polymorpha and the snail Biomphalaria glabrata, using Gramicidin $S$ and $D$ and molluscicidal strains of Bacillus. J Ind Microbiol Biotechnol 18:226-231. https://doi.org/10.1038/sj.jim.2900371

31. Tunholi VM, Lorenzoni PO, da Silva YH et al (2017a) Molluscicidal potential of Heterorhabditis baujardi (Rhabditida: Heterorhabditidae), strain LPP7, o Lymnaea columella (Gastropoda: Pulmonata): An alternative for biological control of fasciolosis. Acta Trop 173:23-29. https://doi.org/10.1016/j.actatropica.2017.05.024

32. Tunholi VM, Tunholi-Alves VM, Monteiro CO et al (2017b) Biological, biochemical and histological features of Bradybaena similaris (Gastropoda: Pulmonata) infected by Heterorabditis indica (Rhabditida: Heterorhabditidae) strain LPP1. Exp Parasitol 179:28-35. https://doi.org/10.1016/j.exppara.2017.06.004

33. World Health Organization (2011) Schistosomiasis: number of people treated worldwide in 2009. Genebra

34. Zare R, Gams W, Evans HC (2001) A revision of Verticillium section Prostrata. V. The genus Pochonia, with notes on Rotiferophthora. Nov Hedwigia. https://doi.org/10.1127/nova.hedwigia/73/2001/51

\section{Figures}

\section{Figure 1}

Hatchability expressed in percentage (\%) of Biomphalaria tenagophila exposed (treated) and not exposed (control) to propagules of the fungus Pochonia chlamydosporia isolate Pc-10. (***) Averages differ significantly each other (mean $\pm \mathrm{SD}$ ). $\mathrm{P}<0.001$ 


\section{Figure 2}

Type 1 interaction in the egg mass (em) surface, characterized by the presence of adhesion of the fungus, chlamydospore (c) to the outer layer (er).

\section{Figure 3}

Type 2 interaction with alteration of the internal (ir) and external (er) egg mass without hyphal penetration in the egg, only in the casing, promoting this morphological alteration indicated by $(\rightarrow)$.

\section{Figure 4}

Transmission electron microscopic images of egg masses of Biomphalaria tenagophila exposed and not exposed to propagules of Pochonia chlamydosporia (isolate Pc-10) after incubation for 15 days. In the control group (Fig. 4A and B), there is no evidence of fungal germinative structures, only rupture of the gelatinous structure of the egg mass (em). In the treated group (Fig. 4B), it is possible to observe the presence of an embryo (e) still developing, in the veliger stage (development of the shell, eyes and foot), as well as adherence of a chlamydospore (chl) and germinative tube (gt) in the egg mass of the planorbid (Fig.4C). Scanning electron microscopic images of egg masses of Biomphalaria tenagophila exposed and not exposed to propagules of Pochonia chlamydosporia (isolate Pc-10) after incubation for 15 days. In the control group (Fig. 4D, E and F), the egg mass (em) is ruptured, with no evidence of germinative structures of the fungus in the interior (int) or exterior (ext) of the structure, and one of the eggs has a thin tegument layer (shell) that is ruptured due to the hatching of the planorbid (Fig. 4F). In the treated group, a mycelial entanglement can be seen covering the external surface (Fig. 4G, $\mathrm{H}$ and I), as well as the presence of chlamydospores (chl) and hyphae (h) also colonizing the inside of the egg mass of the planorbid (Fig. 4H and I).

\section{Figure 5}

Egg masses of Biomphalaria tenagophila not exposed (A) and exposed (B) to fungus Pochonia chlamydosporia (f), from the 15th day of exposure, showing absence of melanization.

\section{Supplementary Files}


This is a list of supplementary files associated with this preprint. Click to download.

- Graph.tif

- Highlights.docx 